\title{
Evaluation of the Effect of Conventional Rhinoplasty with Autospreader Flap and Let- Down Technique on Nasal Functions
}

\author{
Burak Mustafa Taş, MD ${ }^{1}$ Burak Erden, MD² \\ ${ }^{1}$ Department of Ear, Nose, and Throat, Kırıkkale Yüksek ihtisas \\ Hastanesi, Kırıkkale, Turkey \\ 2 Department of Ear, Nose, and Throat, Mersin Province Training and \\ Research Hospital, Mersin, Turkey
}

\begin{abstract}
Address for correspondence Burak Mustafa Taş, MD, Department of Ear, Nose, and Throat, Kırıkkale Yüksek ihtisas Hastanesi, Kırıkkale 71000, Turkey (e-mail: mbtass@hotmail.com).
\end{abstract}

Facial Plast Surg 2021;37:302-305.

\author{
Abstract \\ Keywords \\ - autospreader flap \\ - Let-down technique \\ - NOSE \\ - rhinoplasty \\ - SNOT-22
}

Let-down technique, in which high septal strip resection is performed, and conventional rhinoplasty using autospreader flaps were compared regarding nasal functions with Nasal Obstruction Symptom Evaluation (NOSE) and Sinonasal Outcome Test-22 (SNOT22) quality-of-life scale questionnaires. A total of 54 patients who were included in the study were divided into two groups: group 1 (autospreader group; $n=27$ ) and group 2 (let-down group; $n=27$ ). Open technical septorhinoplasty operation using an autospreader flap was performed in group 1. Let-down rhinoplasty was applied in group 2. NOSE and SNOT-22 scales were filled for the groups in the preoperative and postoperative periods and were compared. Postoperative values were found to be significantly lower than preoperative values in both groups $(p<0.001)$. When the groups were compared in between, no significant difference was seen according to the scales $(p>0.05)$. There was also no significant difference between the groups regarding age and gender. Although there was no significant difference between the two techniques, both NOSE and SNOT-22 quality-of-life scales have shown improvement both in conventional rhinoplasty with autospreader flap and let-down technique.
In conventional rhinoplasty, after the dorsal hump resection, the keystone area and midvault structure are impaired. ${ }^{1}$ The internal nasal valve (INV) may contract due to structural impairment in the nasal midvault. Spreader graft and autospreader flap can be used to avoid a contraction in INV and keep the dorsal aesthetic lines intact. ${ }^{2}$ Autospreader flaps entered our practice as an alternative to spreader grafts. In cases where the upper lateral cartilages are long, an autospreader flap can be used without the need for grafts. The angle of INV is extended with the autospreader flap. ${ }^{3}$ Irregularities in dorsal aesthetic lines can be corrected after dorsal hump resection.

Irregularities in dorsal aesthetic lines after dorsal cartilage and bone hump resection, impairment of keystone area integrity, and contraction of INV are some of the problems in conventional rhinoplasty. Dorsal preservation rhinoplasty
(DPR) has become more popular in recent years to prevent problems such as inverted V deformity caused by dorsal hump reduction or narrowed midvault. Especially in recent years with the developing surgical technique, the let-down (LD) technique has started to be applied. Nasal hump is reduced by wedge resection of the frontal process of the maxilla by septal cartilage resection in $L D{ }^{1,4}$ Since no resection is performed on the nasal dorsum, no irregularity is seen in the dorsal aesthetic lines. ${ }^{5}$ INV and keystone area impairment is not expected.

Nasal Obstruction Symptom Evaluation (NOSE) scale is a quality-of-life scale consisting of five questions about nasal obstruction. The Sinonasal Outcome Test-22 (SNOT-22) is a questionnaire for sinonasal functions, in which questions about nasal obstruction and loss of smell or taste are added to the SNOT-20 scale. published online February 8, 2021
Issue Theme Facial Plastic Surgery Original Research; Guest Editors: Anthony P. Sclafani, MD, MBA, FACS, and Alwyn D'Souza, MBBS, FRCS Eng, FRCS (ORL-HNS) (c) 2021. Thieme. All rights reserved. Thieme Medical Publishers, Inc., 333 Seventh Avenue, 18th Floor, New York, NY 10001, USA
DOI https://doi.org/ 10.1055/s-0041-1722955. ISSN 0736-6825. 
In this study, we compared the effects of LD on nasal functions with conventional rhinoplasty using the autospreader flap through NOSE and SNOT-22 questionnaires.

\section{Materials and Methods}

This study was performed with the approval of the Toros University Scientific Research and Publication Ethics Committee (Decision No: 12). A total of 59 patients were included in the study, but 5 patients who did not come for a control visit were excluded from the study, continuing the study with 54 patients. Patients who underwent LD rhinoplasty and conventional rhinoplasty with autospreader flap between January 2018 and February 2019 were included in the study. A single surgeon operated all patients. The patients were divided into two groups: conventional rhinoplasty group who had an autospreader flap (group $1 ; n=27$ ) and LD rhinoplasty group (group $2 ; n=27$ ). Patients with mild septal deviation and patients with dorsal hump more than $4 \mathrm{~mm}$ were included in the study. NOSE and SNOT-22 questionnaires were filled for all patients scheduled for rhinoplasty before the operation. At least 6 months after the operation, NOSE and SNOT-22 questionnaires were repeated by calling the patients to the hospital between November 2019 and December 2019. Five questions, each scoring between 0 (no problem) and 4 (severe problem), were asked using the NOSE questionnaire, with a total of 20 points. Twenty-two questions were asked using the SNOT-22 questionnaire, with a total of 110 points, and each question was scored between 0 (no problem) and 5 (problem as bad as it can be). The results of the NOSE and SNOT-22 questionnaires before and after the operation were compared. Nasal function results of both groups were compared using NOSE and SNOT22 scales. Scales were compared between the groups using preoperative and postoperative differences. Informed consent was obtained from all patients adhering to the Helsinki Declaration.

Patients who underwent revision septoplasty or rhinoplasty surgery and those who had severe nasal axle deviation and septum deviation, saddle nose deformity, cleft palate-lip deformity, nasal polyposis, and chronic sinusitis were excluded from the study.

\section{Surgical Technique}

All operations were performed under sterile conditions. Transcolumellar open approach was performed on patients in group 1 . Open technique septoplasty was performed after skin elevation in conventional rhinoplasty. Dorsal hump was removed with the help of osteotome and scissors, and then lateral osteotomies were performed. In patients with long upper lateral cartilage, cartilages were folded inwards for bilateral autospreader flap and sutured with 5-0 polydioxanone sutures (PDS II, Ethicon, Somerville, NJ) after elevating the mucosa. Cranial tip suture was used with 5-0 polydioxanone (PDS II, Ethicon) to increase the nasal tip projection and rotation. Various techniques were applied depending on the nasal pathology of the patients (such as bulbous nasal tip or alar retraction). All surgeries were terminated without complications.
All patients in group 2 were operated by high-septal strip resection using the closed approach to $\mathrm{LD}$ technique. The septal flap was elevated to the dorsum following hemitransfixion incision. The incision was made approximately $5 \mathrm{~mm}$ below the dorsum to the ethmoid bone with angled scissors. Then a second incision was made up to the ethmoid bone, based on the height of the hump, and the septal strip was resected to include the ethmoid bone. The remaining subdorsal cartilage was incised to come up to the highest point of the hump, and the dorsum was further mobilized. It was checked how much the dorsum was reduced by pressing it lightly, and septal strip excision was performed if necessary. Appropriate treatment with limited resection as far as possible for the deviated bone and cartilage was performed. Lateral osteotomies were performed and then bone resection was performed from the frontal process of the wedge-shaped maxilla with rongeur forceps. The nasal pyramid was lowered as en bloc by transverse osteotomy. Endonasal tip plasty was performed with the delivery method by preserving the Pitanguy ligament. Cranial tip suture was used to increase rotation and projection in patients, along with dome equalization suture or septocolumellar suture in appropriate patients. Various techniques were applied according to the pathology of the nasal tip, such as cephalic resection and alar batten graft. Septal strip removed was used in patients for whom a columellar strut was going to be placed. All surgeries were terminated without complications.

\section{Statistical Analysis}

SPSS Statistics 21.0 (IBM Corp., Armonk, NY) was used for statistical analysis. The Kolmogorov-Smirnov test and Shapiro-Wilk test were used as normality tests. While preoperative NOSE and SNOT-22 values were normally distributed in group 1, postoperative NOSE and SNOT-22 values were not normally distributed. While preoperative SNOT-22 values were normally distributed in group 2, preoperative and postoperative NOSE values and postoperative SNOT-22 values were not normally distributed. Descriptive statistics related to continuous data were stated as mean \pm standard deviation. The statistical value of $p<0.05$ was considered significant.

\section{Results}

A total of 54 patients were included in our study, with 27 patients in each group. Gender distribution in groups is as shown in - Table 1. The mean age of group 1 was $25.96 \pm 7.583$ years and that of group 2 was $26.52 \pm 7.198$ years. No significant difference was found between the groups in terms of age and gender.

Table 1 Gender distribution in groups

\begin{tabular}{|l|l|l|l|}
\hline & $\begin{array}{l}\text { Group 1 } \\
\text { (autospreader) }\end{array}$ & $\begin{array}{l}\text { Group 2 } \\
\text { (let down) }\end{array}$ & Total \\
\hline Female & $17(63 \%)$ & $14(51.9 \%)$ & $31(57.4 \%)$ \\
\hline Male & $10(37 \%)$ & $13(48.1 \%)$ & $23(42.6 \%)$ \\
\hline Total & $27(50 \%)$ & $27(50 \%)$ & $54(100 \%)$ \\
\hline
\end{tabular}


Table 2 Comparison of groups

\begin{tabular}{|l|l|l|l|}
\hline & $\begin{array}{l}\text { Group 1 } \\
\text { (autospreader), } \\
\text { mean } \pm \text { SD values }\end{array}$ & $\begin{array}{l}\text { Group 2 } \\
\text { (let down), } \\
\text { mean } \pm \text { SD values }\end{array}$ & $p$-Value \\
\hline NOSE & $9.037 \pm 5.452$ & $8.148 \pm 6.099$ & $0.493^{\text {a }}$ \\
\hline SNOT-22 & $24.0 \pm 14.845$ & $28.25 \pm 19.844$ & $0.893^{\mathrm{b}}$ \\
\hline
\end{tabular}

Abbreviations: NOSE, Nasal Obstruction Symptom Evaluation; SNOT-22, Sinonasal Outcome Test-22; SD, standard deviation.

${ }^{a}$ Mann-Whitney $U$ test was used.

b Independent samples $t$-test was used.

Preoperative NOSE values in group 1 and group 2 were $12.96 \pm 5.019$ and $13.04 \pm 5.2266$ respectively, and postoperative NOSE values were $3.93 \pm 3.812$ and $4.89 \pm 4.509$, respectively. Preoperative SNOT-22 values in group 1 and group 2 were $46.30 \pm 18.603$ and $50.11 \pm 18.525$, respectively, and postoperative SNOT-22 values were $22.30 \pm 20.265$ and $21.85 \pm 16.415$, respectively. The postoperative values were observed to be significantly lower than the preoperative values in both groups $(p<0.001)$.

No significant difference was found between the autospreader group and the LD group according to the scales $(p>0.05)$ (-Table 2).

\section{Discussion}

Rhinoplasty is an operation frequently performed by facial plastic surgeons. Although it is an operation performed for aesthetic purposes, it is important to preserve nasal functions. The ideal surgical methods, both aesthetically and functionally, have been sought for years.

Five-question NOSE and 22-question SNOT-22 questionnaires are quality-of-life scales that subjectively evaluate nasal functions., 6 The SNOT-22 questionnaire has a higher specificity for sinonasal functions. In a study by Strazdins et $\mathrm{al}^{8}$ of rhinoplasty patients, NOSE and SNOT-22 scales were assessed together, and significant improvement was found.

Conventional rhinoplasty techniques are preferred by surgeons to see the anatomical structures better, to have more surgical field dominance, and to provide educational purposes. However, especially in recent years, surgeons' desire and need to preserve the anatomical structure as much as possible has led them to DPR techniques. Open roof deformity occurs after dorsal hump reduction. The natural structure of the dorsum is impaired with the dorsal aesthetic lines. Various complications can occur in conventional rhinoplasty, after taking the dorsal hump. These may include midvault and keystone area injuries. Narrow nose, saddle nose, and inverted V deformity may develop. Reconstructing the anatomical structure of the dorsum, which is impaired by conventional rhinoplasty, can prolong surgery time. In addition, the medialization of the lateral nasal wall with lateral osteotomies may adversely affect nasal functions by narrowing the nasal passage. ${ }^{9}$ DPR technique has been reported to be safer by maintaining the anatomical structure of the nasal dorsum and being less invasive. ${ }^{1}$ The structure of the midvault and keystone area is not impaired, and the INV angle is not expected to change. A cadaver study evaluated the effect of DPR on the INV angle, and it was shown that the push down (PD) technique caused contraction, whereas the autospreader flap and LD techniques did not. ${ }^{10}$

The autospreader flap technique is a technique that does not need grafting. It is widely used for midvault reconstruction in suitable patients with short nasal bones, high dorsum, thin skin, and long upper lateral cartilage. ${ }^{3}$ Midvault reconstruction is required to prevent aesthetic and functional problems after dorsum reduction. Especially in thin upper lateral cartilage, there may not be sufficient expansion in the middle roof with the autospreader flap. ${ }^{11}$ Therefore, various modifications of autospreader flaps have been developed. ${ }^{12}$ The common purpose of all modifications is to provide a natural appearance in dorsal aesthetic lines and to prevent possible functional problems by expanding the INV angle. Hussein et $\mathrm{al}^{13}$ showed an improvement in NOSE scores with a modified autospreader flap in a prospective study they conducted. In another study, a modified autospreader technique was again evaluated with NOSE, visual analog scale, and acoustic rhinometry, and was found to be cosmetically and functionally significant. $^{14}$

DPR can be preferred in patients with narrow dorsum and hump. Conventional methods can be used in rhinoplasties requiring grafts (such as saddle nose) and in noses with excessively deviated axes. DPR is a suitable technique, especially in well-selected patients, because it protects soft tissue and dorsum. ${ }^{1,15}$ The fact that it can be done in a shorter time in a less invasive method has increased its popularity. In studies conducted in large series, it was shown to be a safe and protective technique. ${ }^{1,15}$

In our study, the effect of conventional rhinoplasty on nasal functions with LD rhinoplasty and autospreader flap on nasal functions was compared with NOSE and SNOT-22 quality-oflife scales. DPR techniques can be divided into PD and LD. PD technique was applied first. Septal resection is performed in both PD and LD techniques. Various researchers have performed septal resection from different areas. ${ }^{1,4}$ In our study, high septal strip resection was performed while preserving the subdorsal 5-mm cartilage. Studies on DPR techniques, which are becoming more popular today, are limited. Saban et al, ${ }^{1}$ who conducted an extensive study on 320 patients with the DPR technique, used the NOSE questionnaire among 30 patients. Precise recovery was shown in $90 \%$ of patients. ${ }^{1}$ In our study, no significant difference was found between the LD technique and the conventional rhinoplasty applied with autospreader flap regarding nasal functions, according to the scales.

\section{Study Limitations}

Failing to conduct the study in a more extensive series and not using objective methods limit the study. This study can be combined with more specific objective methods for nasal functions.

\section{Conclusion}

Although rhinoplasty is an aesthetic surgical procedure, postoperative functional problems can decrease cosmetic 
satisfaction. In this study, conventional rhinoplasty reconstructed with the autospreader flap and LD technique with high septal strip resection was shown to be subjectively similar in terms of nasal functions. Improvement in postoperative nasal functions was observed in both groups. More extensive studies are needed on the DPR technique, which has a limited number of studies in the literature.

\section{Funding}

None.

\section{Conflict of Interest}

None declared.

\section{References}

1 Saban Y, Daniel RK, Polselli R, Trapasso M, Palhazi P. Dorsal preservation: the push-down technique reassessed. Aesthet Surg J 2018;38(02):117-131

2 Apaydin F. Nasal valve surgery. Facial Plast Surg 2011;27(02):179-191

3 Byrd HS, Meade RA, Gonyon DL Jr. Using the autospreader flap in primary rhinoplasty. Plast Reconstr Surg 2007;119(06):1897-1902

4 Patel PN, Abdelwahab M, Most SP. A review and modification of dorsal preservation rhinoplasty techniques. Facial Plast Surg Aesthet Med 2020;22(02):71-79

5 Tuncel U, Aydogdu O. The probable reasons for dorsal hump problems following let-down/push-down rhinoplasty and solution proposals. Plast Reconstr Surg 2019;144(03):378e-385e

6 Soler ZM, Jones R, Le P, et al. Sino-Nasal outcome test-22 outcomes after sinus surgery: a systematic review and meta-analysis. Laryngoscope 2018;128(03):581-592
7 Stewart MG, Witsell DL, Smith TL, Weaver EM, Yueh B, Hannley MT. Development and validation of the nasal obstruction symptom evaluation (NOSE) scale. Otolaryngol Head Neck Surg 2004; 130(02):157-163

8 Strazdins E, Nie YF, Ramli R, et al. Association between mental health status and patient satisfaction with the functional outcomes of rhinoplasty. JAMA Facial Plast Surg 2018;20(04): 284-291

9 Grymer LF, Gregers-Petersen C, Baymler Pedersen H. Influence of lateral osteotomies in the dimensions of the nasal cavity. Laryngoscope 1999;109(06):936-938

10 Abdelwahab MA, Neves CA, Patel PN, Most SP. Impact of dorsal preservation rhinoplasty versus dorsal hump resection on the internal nasal valve: a quantitative radiological study. Aesthetic Plast Surg 2020;44(03):879-887

11 Manavbaşı YI, Başaran I. The role of upper lateral cartilage in dorsal reconstruction after hump excision: section 1 . Spreader flap modification with asymmetric mattress suture and extension of the spreading effect by cartilage graft. Aesthetic Plast Surg 2011;35(04):487-493

12 Kovacevic M, Wurm J. Spreader flaps for middle vault contour and stabilization. Facial Plast Surg Clin North Am 2015;23(01):1-9

13 Hussein WK, Elwany S, Montaser M. Modified autospreader flap for nasal valve support: utilizing the spring effect of the upper lateral cartilage. Eur Arch Otorhinolaryngol 2015;272(02): 497-504

14 Eren SB, Tugrul S, Ozucer B, Meric A, Ozturan O. Autospreading spring flap technique for reconstruction of the middle vault Aesthetic Plast Surg 2014;38(02):322-328

15 Kosins AM, Daniel RK. Decision making in preservation rhinoplasty: a 100 case series with one-year follow-up. Aesthet Surg J 2020;40(01):34-48 